\title{
Future Skill Development in Undergraduate Students Through Work in STEM OUTREaCH
}

\author{
Lisa Romkey, Tracy Ross and Daniel Munro \\ University of Toronto, Actua \\ lisa.romkev@utoronto.ca, tracv.ross@actua.ca, dan.munro@utoronto.ca
}

\begin{abstract}
This paper represents the experience and self-reported skill development of undergraduate Science and Engineering outreach instructors, who were working primarily online during the global pandemic in 2020. This work is part of a larger multi-year project designed to articulate the learning and employability skills gained by a pan-Canadian group of undergraduates, by way of their training and work experience as youth program Instructors delivering STEM outreach activities for youth. The development of these skills was measured using a post-program survey, in which undergraduate instructors were asked a number of questions about their skill development. Instructors noted development most significantly in (1) teamwork and collaboration; (2) adaptability and flexibility: (3) communication, (4) leadership, (5) innovation and creativity, and (6) initiative.

A significant theme noted was the learning that took place from the sudden shift to teaching remotely and working through a pandemic. Although the focus of STEM Outreach research \& evaluation is often on the impact of the program on its participants, this work demonstrates the value of the instructor experience, and how this work can leverage other post-secondary initiatives designed to prepare undergraduates for their careers.
\end{abstract}

Keywords: Future Skills, Career Development, Professionalism, STEM Outreach, Undergraduate Students

\section{InTRODUCTION}

This paper presents the results of a survey focused on workplace skill development in a population of undergraduate students who are engaged in STEM Outreach instruction across Canada. This work is part of a larger project on learning and employability skill development of STEM outreach program instructors. This work may provide a useful framework for other summer employment and co-curricular programs looking to identity skill development in their participants.

CEEA-ACEG21; Paper XXX

University of Prince Edward Island; June 21 - 23, 2021- 1 of 7 -
Due to the COVID-19 pandemic, the vast majority of programs moved online in 2020, and instructors were given the unique opportunity to adapt programming to the new, remote learning context. The survey, administered upon completion of summer employment, reports on the work experience of instructors working primarily online, and is compared to the experience from the 2019 year, in which regular in-person programming was offered and instructors were assessed on the development of workplace or "future" skills through a quantitative survey and an in-depth qualitative study [15]. Although this work was not designed specifically to measure the impact of online STEM outreach work, we offer some discussion of the impact on instructor skill development as a result of the shift to the remote learning environment.

\section{BaCkground And Conceptual FRAMEWORK}

\subsection{Project Context: STEM Outreach}

Every year, thousands of youth participate in STEM outreach programs delivered by Actua, a national STEM outreach organization, and its network of university and college-based members located across the country. Hundreds of STEM outreach instructors are engaged in facilitating these programs. The instructors are primarily undergraduate students in STEM-related fields at network member organizations - half of which have faculties or schools of engineering and/or applied science that host their programs. The programming models week-long camps, year-round clubs, and school and community-based workshops. Together, Actua and its network engage youth aged 6-16 across 500 communities. They reach every province and territory in Canada and focus on engaging youth from underrepresented groups, such as Indigenous youth, girls in STEM, at-risk youth, newcomers to Canada and youth experiencing socio-economic challenges.

The instructors receive training and deliver programs, and through this experience gain employability and leadership skills. Instructors participate in a mix of local 
and national training, and work collaboratively to research, develop, test and document STEM content and activities for youth. The training offered by the organization and its member programs focuses on a variety of topics, including classroom management, gender equity, Indigenous cultural awareness, curriculum development \& delivery, and working with children who have special needs.

Instructors deliver the programming, typically in a team with 1-2 other instructors. They are responsible for participant supervision, safety, enjoyment and learning. Instructors also interact with parents, faculty members of the home university, and other guests of the program.

\subsection{STEM Outreach Instruction \& Skills Development}

Although there is significant research and evaluation on the experience of STEM outreach participants, there is a gap in the literature on the experience of working in STEM outreach, and the relationship between the work experience and the development of future workplace skill development. While the context is different, we can draw from the literature on staff skill development in a more traditional camp program environment. Recent work in this space has attempted to draw a connection between the staff experience, and preparation for college, career and life success.

In work by Wilson and Sibthorp [20], camp staff demonstrated development in a wide range of skills and competencies, including teamwork and collaboration, self-confidence, organization, responsibility, independence, perseverance, career orientation, and emotion regulation. This work built on previous research which emphasized, in particular, the impact of the camp experience on interpersonal skills and teamwork [4], [18]. Furthermore, a longitudinal study on the development of skills for the future by Povilaitis et al [13] also found evidence of the development of relationship skills and leadership and that, overall, camp employment offers rich opportunities for skill development. A small qualitative study [12] found gains in social-emotional learning, including self-awareness, self-management, social awareness, relationship skills and responsible decision making.

In the work by Wilson and Sibthorp, it was found that the development of these skills was motivated by the experiential nature of the employment, the notion of camp as "separate time and space", the nature of the camp schedule, the roles and responsibilities given to the staff, communal living in safe and supportive environments, and the diversity of people. In particular, camp staff appear to learn a lot from each other and from the process of working together. The exploration of these motivating factors built on previous work [8] that indicated the structure, duration and setting of camp, the nature of experiential learning and staff dynamics all contribute to skill development.

\subsection{Introduction to Future Skills Project}

The Future Skills Project is designed to articulate the learning and employability skills gained by a pan-Canadian group of undergraduate students through training and work experience as outreach program instructors. We also have an interest in the transferability of skills from outreach programming to their future academic and career opportunities. The broader work includes the development of a Future Skills framework.

\subsection{Future Skills Conceptual Framework}

To examine the development of employability skills, a Future Skills framework was developed by Actua. First, a survey was created for instructors, drawing from existing tools. This survey asked instructors about skills developed based on their experience working as an outreach instructor. Second, program directors were interviewed, and were asked about the skill development as reported by the instructors. Simultaneously, a literature review of skills frameworks was conducted, drawing from the Canadian Engineering Accreditation Board's Graduate Attributes [7] and other frameworks, including the University of Toronto Co-Curricular Record [19], The Canadian University Survey Consortium Survey of University Students [14], The National Survey of Student Engagement [11] and the Memorial University Career Integrated Learning Initiative [10]. Finally, interviews were conducted with eight employers representing a variety of industries regarding their hiring processes and competencies sought in new STEM graduates.

The framework provides a useful foundation for measuring and supporting the development of relevant skills and competencies. The documentation and measurement of skill development within the co-curricular and extra-curricular experience is also a priority for universities [5], [6], [17] and so this work should be of interest to our university partners. The work is informed by other initiatives designed to map the development of experiential learning [1], [3] and by private sector initiatives to assist youth in preparing for the workforce [16].

Based on the survey results, interviews and literature review, a set of 12 future skills were developed, organized in three main categories, as outlined in the table below: 


\begin{tabular}{|l|l|l|}
\hline $\begin{array}{l}\text { Delivering } \\
\text { Results: }\end{array}$ & $\begin{array}{l}\text { Working with } \\
\text { Others: }\end{array}$ & $\begin{array}{l}\text { Future } \\
\text { Readiness: }\end{array}$ \\
\hline $\begin{array}{l}\text { Problem Solving } \\
\text { Critical Thinking } \\
\& \text { Analysis }\end{array}$ & $\begin{array}{l}\text { Teamwork \& } \\
\text { Collaboration }\end{array}$ & $\begin{array}{l}\text { Adaptability \& } \\
\text { Flexibility }\end{array}$ \\
Initiative & Communication & $\begin{array}{l}\text { Innovation \& } \\
\text { Creativity }\end{array}$ \\
Commitment & Social Intelligence & $\begin{array}{l}\text { Ability \& } \\
\text { Eagerness to } \\
\text { Learn }\end{array}$ \\
& & \begin{tabular}{l} 
Self-Awareness \\
\hline
\end{tabular} \\
\hline
\end{tabular}

Table 1: Future Skills Framework

\section{Project Methodology}

\subsection{Survey Development}

The work represented in this paper is primarily qualitative, with a smaller quantitative component. Data was collected through a pre and post-work experience survey, which was distributed to program instructors before beginning their STEM outreach work experience, and again upon completion of their summer employment period. Program instructors had the opportunity to rate their confidence in a number of "future skills" on the preand post- surveys, and in the post-survey, respond to open-ended questions about the future skills framework, and their experience. The Future Skills Framework, as described in the previous section, was used to inform the survey development. Some of the survey questions were provided by a funding partner with an interest in experiential learning, while others were developed by the research team to capture a more in-depth examination of future skill development.

\subsection{Data Analysis}

In 2019, 635 instructors participated in the pre-survey and 350 instructors participated in the post-survey, with 201 surveys matched pre and post. In 2020, 313 instructors participated in the pre-program surveys, and 189 participated in the post-program surveys, with 140 paired responses. The decrease was expected, given decreased hiring and survey fatigue in the pandemic. The instructors who participated represent a diversity of academic programs and geographic locations across the country. The vast majority of instructors were conducting remote outreach programming, with a small group conducting a mix of in-person and remote activities. While it would be interesting to compare the instructor skill development of remote and in-person instruction, it would be a problematic comparison given the very non-traditional circumstances of the limited in-person activity; effectively, even instructors who were facilitating in-person programming were also doing remote activities. However, we are able to offer some comparison with data collected in 2019, when programs were running in their typical format.

\section{Results and Discussion}

The pre-and post surveys for both 2019 and 2020 asked outreach instructors to rate their confidence level on a set of practices representing the future skills. These quantitative survey responses demonstrated growth in instructor confidence in some of the Future Skills over the duration of the program. The quantitative responses on pre- and post- comparison of skill confidence were tabulated; instructors rated their confidence on a scale of 1-10, with 1 meaning "not at all confident" and 10 indicating "very confident". Mean scores based on paired responses for each of the skills are summarized in Table 2.

\begin{tabular}{|l|c|c|}
\hline \multicolumn{1}{|c|}{ Skill Area/Question } & \multicolumn{2}{|c|}{ Average Score /10 } \\
\hline & 2019 & 2020 \\
\hline Critical Thinking & Pre: 7.98 & Pre: 8.11 \\
& Post: 8.36 & Post: 8.21 \\
\hline Problem Solving & Pre: 8.15 & Pre: 8.15 \\
& Post: 8.31 & Post: 8.11 \\
\hline Persistence/Grit & Pre: 4.56 & Pre: 4.56 \\
& Post: 4.62 & Post: 4.56 \\
\hline Collaboration & Pre: 8.01 & Pre: 7.87 \\
& Post: 8.27 & Post: 8.12 \\
\hline Communication & Pre: 7.64 & Pre: 7.51 \\
& Post: 8.07 & Post: 7.74 \\
\hline Creativity & Pre: 7.55 & Pre: 7.50 \\
& Post: 7.75 & Post: 7.72 \\
\hline Digital Literacy & Pre: 8.72 & Pre: 8.53 \\
& Post: 8.62 & Post: 8.81 \\
\hline
\end{tabular}

Table 2: Skills with an Increase in Confidence

It's worth noting that overall, the participants began the STEM outreach experience reporting very high confidence in their future skills, and in the case of several skills, there was no significant change over the baseline measurement. In the case of some skills - critical thinking, problem solving, persistence/grit and communication, the impact was greater under normal operating circumstances. In the case of collaboration and creativity, the change in 
confidence was virtually the same under both in-person and primarily remote learning. As expected, instructors expressed more confidence in their digital literacy skills after working through the pandemic as compared to normal operating circumstances in 2019. Overall, it would seem that the skill development was negatively impacted, albeit modestly, by the switch to remote program delivery. However, some of the qualitative analysis demonstrated the perceived value of working through the challenges of the pandemic, which is described later in this section.

Instructors were asked about whether they felt more prepared for the workforce after participating in the program; $83 \%$ of the instructors indicated they felt more prepared in 2020. In 2019, 76\% indicated they felt more prepared; this modest increase from 2019 to 2020 might be linked to a perception that remote teaching and facilitation is more career-relevant, given the application of digital skills. While these results demonstrate that the majority of instructors are implicitly linking their STEM outreach experience to their future career, there are a number $(17 \%$ in 2020$)$ who are not, showcasing the need to educate the STEM outreach instructors on the relevance of the training and work experience.

In 2020, instructors were asked additional questions about their experience in the post-program survey. The remaining analysis presented focuses specifically on the 2020 post-program survey responses. Instructors were asked to name their top three competencies developed while working as a STEM outreach instructor. Over 75\% of responses matched six competencies, in order of highest to lowest frequency of responses: (1) teamwork and collaboration, (2) adaptability and flexibility, (3) communication, (4) leadership, (5) innovation and creativity, and (6) initiative. Instructors expressed an interest in developing further skills in building networks; our assessment based on previous work [15] is that STEM outreach instructors may not see their outreach experience as an opportunity to build a network, and instructors may need scaffolding and support to recognize that STEM outreach can be a tremendous networking opportunity.

Instructors were asked to describe how they developed their top three competencies. This offered a rich description of the instructor experience and the process of skill development. 187 participants responded to this question; responses have been organized by theme as identified through thematic analysis, rather than by competency specifically.

\section{Theme: The challenges of the pandemic \& working online $(\mathbf{n}=\mathbf{8 2})$}

The most significant theme identified in the data is the learning that took place from the sudden shift to teaching remotely and working through a pandemic. Despite the survey analysis described above which compared self-reported skill development in 2019 and 2020 (with a modest decline in 2020), instructors spoke about the value of learning to work and collaborate online, and more broadly the value of having to adapt and be flexible when it came to delivery modes and methods. Instructors cited skills like "willingness to learn", "creativity" and "agility" to be of critical importance, alongside the importance of "independent work" and "taking initiative" as instructors worked remotely from home.

Instructors also reflected on the importance of working together towards a common goal - through effective communication and teamwork - to work through the challenges of pivoting to remote teaching. For team leads, there were new decisions to be made about how to communicate, lead and facilitate programming and team management.

Using specific tech tools to facilitate both planning and online learning also contributed to the skills and competencies learned because of the pandemic. Instructors noted that their communication skills and perception of student needs increased as new limitations were placed on the learning environment.

"The unique challenges presented by pivoting from in-person camps allowed me as an employee to work on my skills related to agility and willingness to learn. Using online platforms to communicate with others enabled the application of pre-existing communication skills as well as the development of new communication skills specific to digital interfacing."

"Being able to lead a team virtually required me to adapt $\&$ focus on different forms of communication.I had to think way more critically about decisions, communication and leadership because it all was so much more intentional."

"It was amazing to see how my workplace was able to adapt to an online format. Having worked with this in-person the year previous their online work was amazing. I didn't expect this and being able to adapt to this was a fun and challenging experience"

\section{Theme: Working with others leads to skill development $(\mathbf{n}=\mathbf{5 7})$}

A large number of instructors reported that they developed skills - including but not limited to "teamwork" - through working with others. Participants spoke to the value of working with others collaboratively and the importance of diversity in the team; and how they learned to ask for help and communicate with others when learning something new, effectively supporting each others' development. Participants also spoke to the learning that takes place through observing others and modelling their approach, and the development of skills through feedback from team leadership. 
"My job is mainly based on teamwork. All of us are working together to create the best content for kids as possible. It wouldn't be possible without working together. When working with a team the key thing you need for it to go smoothly is communication. We are constantly in communication with each other and I have learned that it's okay to ask questions when you don't understand or are learning something new."

"Through this job I have had the opportunity to develop these competencies both through the role requirements and also through learning by the example of others (eg. watching a TL and modelling their behaviour when teaching)."

"For social perceptiveness I worked with a lot of very different children and a handful of coworkers from diverse backgrounds so I was able to learn more about and observe the personalities and actions of so many different people which helped me to become more socially perceptive."

Furthermore, instructors were asked, through the post-program survey, "Consider the training you received this summer. Which aspects of the training best helped to prepare you for working with this program?" While several students cited specific training sessions, a significant theme in the data was that instructors identified and spoke highly of "training" opportunities that existed simply through interacting with others. The instructors explained a number of specific mechanisms; including: (1) working with more experienced instructors who acted as role models and provided informal training; (2) a general openness to discussion, group planning and ongoing learning through regular meetings and communication; (3) opportunities to witness the work of other instructors and then model their approach; (4) reflection as a group on instructor learning; (5) ongoing feedback and clear guidelines from program leadership and senior instructors; (6) diversity in the team and (7) general support between team members with the focus on a common goal.

"The morning meetings every morning helped me get over my nervousness in talking in front of groups as well as forced me to think outside the box in many different brainstorming situations."

"I think the training which helped the most was shadowing/working with others who had participated previously and already had a good idea of what they were doing. I got to learn through observing and helping rather than entirely trying to learn in a training session based on theory."

"Meeting with the admin staff to collaborate and come up with ideas for how the camp can run smoothly was most helpful. I enjoyed open group discussions and hearing everyone's perspectives on how we can improve our programs."

"The teamwork aspects of training probably helped the most as none of us could have gotten through this summer without each other."

\section{Skill development through teaching $(n=32)$}

Several instructors described skill development through teaching or program delivery. Working to ensure STEM concepts and activities were well-explained and facilitated based on the unique needs of the participant group encouraged the development of leadership, communication and presentation skills, and further scientific and engineering understanding. Instructors also noted that they are required to consider how others learn and interpret things, which links to improved social perceptiveness.

"Delivering the content to students also taught me to think about and consider how others learn and interpret things."

"Instructing coding and science workshops for students sparked my interest in some subjects and encouraged me to work on developing relevant skills learned about many different types of engineering projects throughout the summer."

"I had never coded in Python or Javascript before so learning it in a short time span to be able to teach it was a very motivating way to learn those languages faster than I would have on my own time."

\section{Activity and content development $(n=29)$}

Linked to the previous category, instructors also described competency development through their own activity and content development. Instructors noted that developing engaging and original programming for the participants sparked creativity and innovation. Instructors noted the importance of taking initiative, driving the process and bringing the work to completion. Further creativity and flexibility was developed through a requirement to modify activities for missing materials in the participant home (due to remote teaching). Instructors also cited the value of learning new things so that they could then effectively deliver material, and how this provided a strong motivation to learn something new.

"By creating new and original content for camps this has been the most creative I've had to be in any job I've worked for." 


\begin{abstract}
"Working for any STEM summer camp requires innovation and creativity when working on activities and design challenges to get the kids thinking and learning!"

"I developed initiative through working independently and needing to make decisions on my own in order to proceed with program development."
\end{abstract}

\section{Adaptability through the inherent nature of the work $(\mathbf{n}=\mathbf{2 1})$}

Even without a pandemic, working with a STEM Outreach program requires instructors to be flexible in their approach, to improvise when the unexpected happens, and to use creativity and on-the-spot decision making. The instructors spoke about how the nature of facilitating STEM programming supports the development of a number of skills, in particular flexibility and open-mindedness, adaptability, problem solving and initiative.

"I quickly developed better adaptability and flexibility to be more open minded and able to change plans if something is not working out."

"Commitment as this job takes a lot of energy and you need to be committed to keep going. Adaptability as this job can change at any second (and) you need to be prepared."

"Adaptability is a big part of this program as well as communication. I am constantly having to reexplain myself and come up with new challenges and changes to the activities I have planned.

Being put into a leadership position where different problems would arise each day and having to solve them."

"This job put me out of my comfort zone and that is what I think I like most about this position. I have learnt so much and I have a whole new respect for the field of computer science as a whole!"

\section{Conclusions and Future Work}

This work reports on the self-reported skill development in STEM outreach instructors, highlighting the value of this work experience to undergraduate students seeking employment in STEM related industries after graduation. An increase in self-reported confidence was noted in the case of several future skills. Instructors also discussed the mechanisms for skill development; in particular, working through the challenging circumstances of the pandemic; working with others; skill development through teaching and curriculum development, and the required flexibility that is inherent to the job.

The results of this study resonate with the research that has been conducted with staff from more traditional camp programs; although the context is different, camp-based research offers a useful complement to the examination of the STEM outreach program experience. In particular, the development of teamwork, collaboration and social awareness skills is salient across both contexts, and the value of learning with/from others, which was also apparent in a small qualitative study we completed in 2019 [15]. Based on the results of this and previous work, there may be opportunity to use the instructor outreach experience as a laboratory for the study of collaborative learning, reflecting on Bandura's social cognitive theory [2], which explains the learning that is generated from observing and interacting with others, and situated learning [9] which describes learning taking place through interactions between people and their environment. Developing a better understanding of how STEM outreach instructors learn together and from each other could prove useful in other contexts, such as team-based design and other collaborative learning contexts in STEM.

In future work, we will continue to make an effort to validate the future skills framework within the context of the outreach experience, in an effort to demonstrate to students and employers that working as a STEM outreach instructor can serve as excellent preparation for a post-graduate career in STEM. As noted by Wilson \& Sibthorp [20] in the camp context, there is an opportunity in STEM outreach to further the intentionality of outreach work experience as a mechanism for academic and workplace readiness. Finally, a number of new training modules are under development to support the future skills, and these will be evaluated and presented in future work.

\section{Acknowledgements}

We would like to acknowledge RBC Foundation for their valued investment, in support of RBC Future Launch, toward Actua's Future Skills Project. We would also like to acknowledge the STEM outreach instructors who shared their perspectives.

All procedures performed in studies involving human participants were in accordance with the ethical standards of the University of Toronto Research Ethics Board.

\section{References}

[1] Academica Group and Business/ Higher Education Roundtable. "Taking the Pulse of Work Integrated Learning in Canada”. Academica Group, London, Ont., Canada. Accessed on: February 3, 2020 [Online]. Available 
http://bher.ca/publications/taking-the-pulse-of-work-integrated-1 earning-in-canada-full-report

[2] A. Bandura, Social Foundations of Thought and Action: A Social Cognitive Theory. Englewood Cliffs, NJ: Prentice Hall, 1986.

[3] E. Bowering, C. Frigault and A. Yue, "Preparing Undergraduate Students for Tomorrow's Workplace: Core Competency Development through Experiential Learning Opportunities." Canadian Journal of Career Development, vol 19 , issue $1,2020$.

[4] L. Collins. "The Meaning of Camp and Social Group Work Principles", Social Work with Groups, vol. 29, no. 2-3, 133-148, 2006.

[5] D. Drolet, "Documenting and decoding the undergrad experience," University Affairs, vol. 51, pp. 10-15, Aug. 2010.

[6] K. Elias and C. Drea, "The Co-Curricular Record: Enhancing a Postsecondary Education," College Quarterly, vol 16, Jan. 2013.

[7] Engineers Canada."Canadian Engineering Accreditation Board 2019 Accreditation Criteria and Procedures." Engineers Canada, Ottawa, Ont., Canada, Dec. 2019. Accessed on: February 3, 2020. [Online] Available https://engineerscanada.ca/sites/default/files/accreditation/Accre ditation-Criteria-Procedures-2019.pdf

[8] B.A. Garst, L.P. Browne and M.D. Bialeschki. Youth development and hte camp experience. New directions for student leardership, 2011(130), 73-87.

[9] J.G. Greeno, A.M. Collins and L.B. Resnick, "Cognition and Learning", in Handbook of Educational Psychology, R. Calfee \& D. Berliner, Eds., New York: Macmillan, 1996.

[10] Memorial University of Newfoundland and Labrador. "Career Integrated Learning: A grassroots approach to creating awareness of graduating student competencies". Presentation at Canadian Association of Career Educators and Employers meeting, May 27, 2014. St. John's, NL. Accessed on: August 8, 2016 [Online] Available: https://www.mi.mun.ca/media/marineinstitutewwwmimunca/mi/ careerintegratedlearning/files/CACEEpresentation2014.pdf

[11] National Survey of Student Engagement. "NSSE 2016 Survey Instrument (Canadian English)." Indiana University, Bloomington, Indiana. 2016. Accessed on: August 82016 [Online].

Available http://nsse.indiana.edu/pdf/survey instruments/2016/NSSE 201 6-Canadian English.pdf

[12] M. Owens and A. Wahle, "Camper Leaders' Work-Related Experiences for Social-Emotional Learning”. In Proc. 2018 American Camp Association Research Forum, 2018, pp. 40-43.

[13] V. Povilaitis, J. Sibthorp and R. Richmond. "Camp Employment as a Developmental Setting for Emerging Adults: A National Mixed-Methods Study". Journal of Outdoor Recreation, Education \& Leadership, vol. 13, no. 1, 2021.

[14] Prairie Research Associates and Canadian University Survey Consortium, "2013 First-year University Student Survey Master Report." 2013. Accessed on: August 8, 2016 [Online]. Available: https://cusc-ccreu.ca/?page id=32\&lang=en

[15] L. Romkey and T. Ross, "Post-Secondary Work Integrated Learning through STEM Outreach", in Proc. ASEE Annual Conference, Long Beach, California, 2021.

[16] Royal Bank of Canada. "Humans Wanted: How Canadian Youth Can Thrive in the Age of Disruption". Royal Bank of Canada, Toronto, Ont., Canada, Oct. 2018. Accessed on: February 3, $2020 \quad$ [Online]. Available https://thoughtleadership.rbc.com/humans-wanted-canadian-you th-can-thrive-age-disruption/

[17] A.E. Stirling and G.A. Kerr, "Creating Meaningful Co-Curricular Experiences in Higher Education," Journal of Education and Social Policy, vol. 2, Dec. 2015.

[18] C. Thurber, M. Scanlin, L. Schueler, and K. Henderson. "Youth Development Outcomes of the Camp Experience: Evidence for Multidimensional Growth". Journal of Youth Adolescence, vol 36, pp. 241-254, 2007.

[19] University of Toronto Career \& Co-Curricular Learning Network, 'U of T Co-Curricular Record', 2019. Accessed on February 3, 2020 [Online]. Available: https://clnx.utoronto.ca/ccr/overview.htm

[20] C. Wilson and J. Sibthorp. "Examining the Role of Summer Camps in Developing Academic and Workplace Readiness. Journal of Youth Development, vol. 13, no. 1-2, 2018. 